\title{
POST CHOLECYSTECTOMY AND THE DYSPEPTIC PATIENT TO IDENTIFYING THE APPROPRIATENESS OF OPERATIVE INTERVENTION IN CHENGALPATTU MEDICAL COLLEGE
}

\author{
Shantha Kumar Kuzhanthaivelu ${ }^{1}$
}

${ }^{1}$ Associate Professor, Department of General Surgery, Chengalpattu Government Medical College and Hospital.

\section{ABSTRACT}

\section{BACKGROUND}

Dyspepsia is defined by the discomfort or pain localised in the upper abdomen. This pain is common with a prevalence of forty to sixty percent in the general population. But often 55\% of patients do not have any underlying abnormality after doing upper GI investigations, but yet remain symptomatic. Dyspeptic symptoms can present for at least twenty five percent of times for a period of one month in absence of a definite disease. This is called as functional dyspepsia.

The aim of the study was to identify whether early surgery in patients with uncomplicated gall stone disease and symptom of dyspepsia will give complete symptom resolution post-operatively. Based on this, we identified the appropriate timing interval of laparoscopic cholecystectomy for patients with uncomplicated gall stone disease and symptom of dyspepsia.

The research objectives were-

1. To analyse if laparoscopic cholecystectomy in patients with gall stones and symptom of dyspepsia will give entire relief of symptom. The word entire relief of symptom means entire cessation of symptom of dyspepsia after LC.

2. To compare the changes in the pre-operative scores to the post-operative scores and satisfaction after LC in these two groups of patients, i.e. patients with gall stones and dyspeptic symptoms and patients with gall stones and no dyspeptic symptoms.

3. To determine the relationship between the duration of pre-operative episode and the complete resolution of symptoms following LC in patient with gall stones and symptom of dyspepsia. Duration is measured by the total time period between onset of symptom and LC.

4. To determine the relationship between the frequency of pre-operative episode and the complete resolution of symptom after LC in patient with gall stones and symptom of dyspepsia. Frequency is measured by the number of episodes in the period of time prior to LC.

\section{MATERIALS AND METHODS}

This observational study was carried out in Government Chengalpattu Medical College and Hospital Institution over a period of 1 year. All patients more than 18 years of age with uncomplicated gall stone disease attending our OPD was found to have gallstones disease by clinical examination and USG abdomen were included in this study. Sixty patients entered the study. Thirty patients $(50 \%)$ had symptoms of dyspepsia (Group I) and thirty patients (50\%) had no symptoms of dyspepsia (Group II). All patients were administered survey questionnaire, which deals with two aspects before surgery and 3 months after LC. This survey contains the validated dyspepsia score of "Buckley et al."

\section{RESULTS}

After laparoscopic cholecystectomy, majority of the patients (76.7\%) in Group I (dyspeptic) achieved complete symptomatic relief 3 months after the surgery as defined by a post-operative Buckley scores of less than 6. Only 23.3\% of Group I (Dyspeptic) patients achieved a Buckley score more than 6. Based on the satisfaction after the surgery, $90 \%$ of Group I (dyspeptic) patients were either very satisfied or satisfied after surgery.

\section{CONCLUSION}

The inference of this study shows that Laparoscopic cholecystectomy in patients with gall stones and symptoms of dyspepsia got a better relief of dyspeptic symptoms post-operatively. Early timely intervention showed a significant change in the pre-operative to the post-operative symptoms and also a significant improvement in satisfaction after the surgery in the two groups of patients. Also the patients who had the symptoms for less than 3 months showed a better improvement in dyspeptic symptoms than the patients who had the symptoms for more than 3 months. ${ }^{3}$ The patients who had the symptoms for less than or equal to 3 episodes showed a better outcome overall.

\section{KEYWORDS}

Cholecystectomy, Dyspepsia, Buckley's Validated Dyspeptic Symptom Score.

HOW TO CITE THIS ARTICLE: Kuzhanthaivelu SK. Post cholecystectomy and the dyspeptic patient to identifying the appropriateness of operative intervention in Chengalpattu Medical College. J. Evolution Med. Dent. Sci. 2017;6(91):6422-6426, DOI: $10.14260 /$ Jemds/2017/1397

Financial or Other, Competing Interest: None.

Submission 31-07-2017, Peer Review 24-08-2017,

Acceptance 30-08-2017, Published 27-11-2017.

Corresponding Author:

Dr. Shantha Kumar Kuzhanthaivelu,

Associate Professor, Department of General Surgery,

Government Chengalpattu Medical College and Hospital.

E-mail:drkskumarmmc@gmail.com

DOI: $10.14260 /$ jemds $/ 2017 / 1397$

(c) (i) $\$$

\section{BACKGROUND}

Among the biliary tract pathology, gall stones are the most common cause of the disease in the adult. Gall stones are mainly divided into 3 types- Cholesterol stones, Pigment stones (Black or Brown) and Mixed stones. In US and Europe, $80 \%$ are Cholesterol or Mixed stones and in Asia $80 \%$ of stones are Pigment stones. Any condition which increases the cholesterol secretion in bile or reduces the bile salt concentration in bile leads to the formation of cholesterol 
stones. Cholesterol stones are formed by cholesterol crystal nucleation, super saturation and reduced gallbladder motility. 4

Pigment stones can be formed as a result of obstruction to the outflow of bile, bacteria ascent from duodenum to gallbladder and alteration in the bile bilirubin. Symptoms of gall stones are mostly- Nonspecific abdominal discomfort, Heartburn, Nausea, Vomiting, Belching or Burping, Flatulence, Fatty food intolerance. The usual complications of gall stone disease are acute and chronic cholecystitis, common bile duct stone (choledocholithiasis), cholangitis, gallstone pancreatitis, cholecystoenteric fistula ${ }^{5}$, obstructive jaundice and carcinoma of the gallbladder very rarely. ${ }^{6}$ In the gallstones disease, only less than twenty percent of patients develop symptoms in which 1 to 2 percent develop serious symptoms and complications, so treatment is usually indicated for relief of symptoms and complications. It is clearly stated in the literature that post laparoscopic cholecystectomy (LC) pain is dependent on the long duration of pain symptom and dyspeptic symptoms. ${ }^{3}$ This analytical study was designed to identify whether early surgery in patients with uncomplicated gall stone disease and symptom of dyspepsia will give complete symptom resolution postoperatively assessed by Buckley's Validated Dyspeptic Symptom Score. ${ }^{7}$ Based on this, we could identify the appropriate timing interval of laparoscopic cholecystectomy for patients with uncomplicated gall stone disease and symptom of dyspepsia.

\begin{abstract}
Aims and Objectives
The aim of this study was to find out the appropriate timing of laparoscopic cholecystectomy in patients with uncomplicated gallstones disease and dyspeptic symptoms and to establish if the patients get complete symptomatic relief post-operatively. This study analysed- 1) Whether laparoscopic cholecystectomy in patients with gallstones and symptom of dyspepsia will give entire relief of symptom. The word entire relief of symptom means entire cessation of symptom of dyspepsia after LC; 2) Compared the changes in the pre-operative scores to the post-operative scores and satisfaction after LC in these two groups of patients, i.e. patients with gall stones and dyspeptic symptoms and patients with gall stones and no dyspeptic symptom; 3) Determined the relationship between the duration of preoperative episode and the complete resolution of symptoms following LC in patients with gall stones and symptom of dyspepsia. Duration is measured by the total time period between onset of symptom and the LC; 4) Determined the relationship between the frequency of pre-operative episode and the complete resolution of symptom after LC in patient with gall stones and symptom of dyspepsia. Frequency is measured by the number of episode in the period of time prior to LC.
\end{abstract}

\section{MATERIALS AND METHODS}

This Observational study was carried out in Government Chengalpattu Medical College and Hospital Institution over a period of 1 year from October 2015 to September 2016 after obtaining the approval from the Institutional Ethical Committee and conducted according to good clinical practice guidelines. All patients attending our institution found to have gallstones disease by clinical examination and investigations were included in this study. Data collected was analysed using chi-square and Wilcoxon Rank-Sum test.

\section{Inclusion Criteria}

All the patients more than 18 years of age with uncomplicated gall stone disease in Government Chengalpattu Medical College and Hospital.

\section{Exclusion Criteria}

(a) Gallstone pancreatitis.

(b) Cholangitis.

(c) Previous choledocholithiasis (common bile duct stone).

(d) Cholecystoenteric fistula.

(e) Obstructive jaundice.

(f) Pregnant women.

(g) Previous pancreatic or biliary surgery.

(h) Carcinoma of Gallbladder.

\section{Recruitment and Identification of Patients with Dyspepsia}

Patients who have gall stones and symptom of dyspepsia (Group I) 30 patients (50\%) and those patients with gall stones but without symptom of dyspepsia (Group II) 30 patients (50\%) were compared based on the validated dyspeptic scores as defined by Buckley et al. The sample size of 30 was taken for convenience. Hence, a total of 60 patients who fulfilled the following eligibility criteria were included in the study.

\section{The Survey Questionnaire}

Our survey deals with two aspects before surgery and 3 months after LC. This survey contains the validated dyspepsia score of "Buckley et al." The questionnaire contains the following pre-operative variables of-

i. Frequency of symptom,

ii. Duration of symptom,

iii. Dyspeptic Buckley score,

iv. Ultrasound abdomen.

The post-operative variables are-

i. Satisfaction after surgery,

ii. Time since surgery,

iii. Post-operative Buckley score.

The three-point scale is used to measure the postoperative satisfaction of the patients by "satisfied, very satisfied or not satisfied." Post-operative. Buckley's score of 6 or less is tabulated as complete cessation of symptoms.

\section{The Validated Dyspepsia Score}

The information from the questionnaire provide a means to calculate the validated dyspepsia scores. A Likert scale is used. The total Buckley symptom score is calculated by the sum of individual severity, frequency and duration score with the following symptom-

1) Epigastric pain.

2) Heartburn.

3) Burping or belching.

4) Bloating.

Each of the above items was scored on a scale severity of 0 to 5 , frequency of 0 to 4 and duration of 0 to 3 . The preoperative and post-operative Buckley score was calculated by simple addition of all the above items score. By using the validated dyspeptic scores as defined by Buckley et al, a score 
of 16 or more defined those patients with symptom of dyspepsia. A score of 6 or less is defined as normal patients that were not symptomatic with respect to dyspepsia. Proforma was used to collect required information.

\section{RESULTS}

\section{Characteristic of Study Groups}

Characteristic of all study participants and two groups were compared and displayed in Table 1 . The mean age of the study participants is 41.8 years (range of 19 - 75). In our study, majority of the study samples consisted of females. All the patients $(100 \%)$ had gallstones on ultrasound.

30 patients (50\%) were in Group I and 30 patients $(50 \%)$ were in Group II. There was no significant difference between these two groups in terms of-

1) Age.

2) Sex.

3) Duration of symptom.

4) Time of surgery.

5) Frequency of episodes.

\begin{tabular}{|c|c|c|}
\hline Characteristics & Group I (30) & Group II (30) \\
\hline Age & 19 to 75 years & 19 to 60 years \\
\hline Male & $6(20 \%)$ & $5(16.7 \%)$ \\
\hline Female & $24(80 \%)$ & $25(83.3 \%)$ \\
\hline \multicolumn{3}{|c|}{ Duration of Symptom (Months) } \\
\hline Less than 3 months & $5(16.7 \%)$ & $6(20 \%)$ \\
\hline More than 3 months & $25(83.3 \%)$ & $24(80 \%)$ \\
\hline \multicolumn{3}{|l|}{ Frequency of Episodes } \\
\hline Less than 3 Episodes & $6(20 \%)$ & $4(13.3 \%)$ \\
\hline More than 3 Episodes & $24(80 \%)$ & $26(86.7 \%)$ \\
\hline \multicolumn{3}{|l|}{ Satisfaction } \\
\hline Not Satisfied & $3(10 \%)$ & $1(3.3 \%)$ \\
\hline Satisfied & $7(23.3 \%)$ & $8(26.7 \%)$ \\
\hline Very Satisfied & $20(66.7 \%)$ & $21(70 \%)$ \\
\hline \multicolumn{3}{|c|}{ Timing of Surgery } \\
\hline 3 months & $5(16.7 \%)$ & $6(20 \%)$ \\
\hline 6 months & $10(33.3 \%)$ & $7(23.3 \%)$ \\
\hline 12 months & $8(26.7 \%)$ & $7(23.3 \%)$ \\
\hline 18 months & $6(20 \%)$ & $8(26.7 \%)$ \\
\hline 24 months & $1(3.3 \%)$ & $2(6.7 \%)$ \\
\hline \multicolumn{3}{|c|}{$\begin{array}{l}\text { Table 1. Clinical Data of Group I (Dyspeptic) } \\
\text { and Group II (Non-Dyspeptic) }\end{array}$} \\
\hline
\end{tabular}

Comparison of Total Pre-operative to Total Postoperative Buckley Scores

Mean cumulative scores of each group were shown in Table 2. For both groups, there was a substantial change in score between the pre-operative and post-operative Buckley score, which were very significant. Chart 1 and 2 shows the distribution of Buckley score before and after surgery for Group I and Group II. These charts reinforce visually the substantial change between the pre-operative and postoperative Buckley score for both the groups.

\begin{tabular}{|c|c|c|}
\hline \multicolumn{3}{|c|}{ Group I } \\
\hline Item & Pre-op & Post-op \\
\hline Scores & $27.4(17-40)$ & $6.7(3-22)$ \\
\hline Table 2a. Comparison of Buckley Scores- Pre-operative vs. \\
Post-operative (Group I)- Median
\end{tabular}

\begin{tabular}{|c|c|c|}
\hline \multicolumn{3}{|c|}{ Group II } \\
\hline Item & Pre-Op & Post-0p \\
\hline Score & $11.5(8-15)$ & $4.5(3-9)$ \\
\hline \multicolumn{2}{|c|}{ Table 2b. Comparison of Buckley Scores- Pre-Operative } \\
Score vs. Post-operative Score (Group II)-Median \\
\hline
\end{tabular}

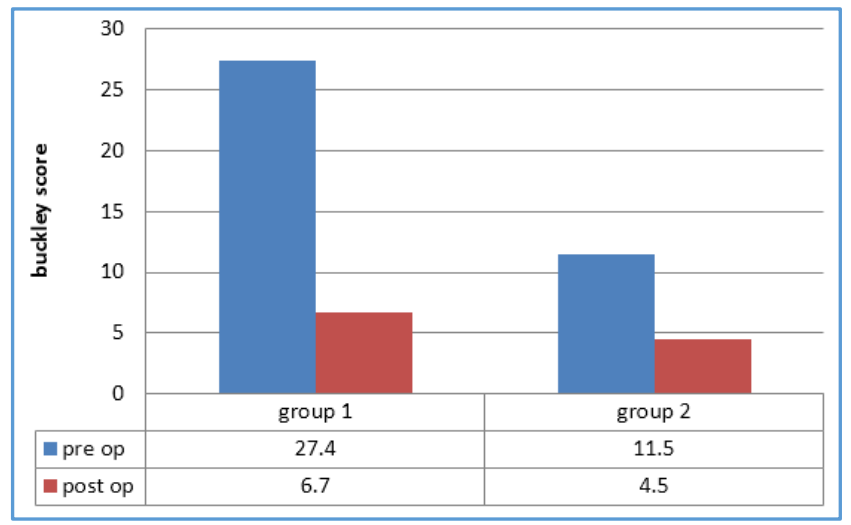

Chart 1. Total Pre-operative and Post-operative Buckley Scores for Group 1 and 2

Comparison of Pre-operative to Post-operative Buckley Score for each of the Symptoms

Tables 3 and 4 showed the before and after the surgery Buckley score for each of the symptoms for Group I and Group II. Both group of patients are found to have significant improvement in all the symptoms- Epigastric pain, heartburn, belching/ burping and bloating.

\begin{tabular}{|c|c|c|c|}
\hline In Items & Pre-Op & Post-Op & P value \\
\hline \multicolumn{4}{|c|}{ Epigastric Pain } \\
\hline Severity (0-5) & $3(1-5)$ & $0(0-2)$ & 0.002 \\
\hline Frequency (0-4) & $2(1-4)$ & $0(0-2)$ & 0.002 \\
\hline Duration (0-3) & $2(1-3)$ & $0(0-2)$ & 0.002 \\
\hline Heartburn & & & 0.002 \\
\hline Severity & $2(1-5)$ & $0(0-2)$ & 0.002 \\
\hline Frequency & $2(1-4)$ & $0(0-2)$ & 0.002 \\
\hline Duration & $2(1-3)$ & $0(0-2)$ & 0.002 \\
\hline \multicolumn{4}{|c|}{ Belching/ Burping } \\
\hline Severity & $2(1-5)$ & $0(0-2)$ & 0.002 \\
\hline Frequency & $2(1-4)$ & $1(0-2)$ & 0.002 \\
\hline Duration & $2(1-3)$ & $1(0-2)$ \\
\hline \multicolumn{4}{|c|}{ Bloating } \\
\hline Severity & $3(1-5)$ & $1(0-2)$ & 0.002 \\
\hline Frequency & $2(1-4)$ & $0(0-2)$ & 0.002 \\
\hline Duration & $2(1-3)$ & $0(0-2)$ & 0.002 \\
\hline Table 3. Comparison of Buckley Score for Group I- \\
Dyspeptic (Median Value) \\
\hline
\end{tabular}

\begin{tabular}{|c|c|c|c|}
\hline In Item & Pre-operative & Post-operative & P value \\
\hline \multicolumn{4}{|c|}{ Epigastric Pain } \\
\hline Severity & $1(0-2)$ & $0(0-2)$ & 0.003 \\
\hline Frequency & $1(0-2)$ & $0(0-2)$ & 0.003 \\
\hline Duration & $1(0-3)$ & $0(0-2)$ & 0.003 \\
\hline \multicolumn{4}{|c|}{ Heart Burn } \\
\hline Severity & $1(0-2)$ & $0(0-2)$ & 0.003 \\
\hline Frequency & $1(0-3)$ & $0(0-2)$ & 0.003 \\
\hline Duration & $1(0-3)$ & $0(0-2)$ & 0.003 \\
\hline \multicolumn{5}{|c|}{ Belching/ Burping } \\
\hline Severity & $1(0-4)$ & $0(0-2)$ & 0.003 \\
\hline Frequency & $1(0-3)$ & $0(0-2)$ & 0.003 \\
\hline Duration & $1(0-2)$ & $0(0-2)$ & 0.003 \\
\hline \multicolumn{4}{|c|}{ Bloating } \\
\hline
\end{tabular}




\begin{tabular}{|c|c|c|c|}
\hline Severity & $1(0-2)$ & $0(0-2)$ & 0.003 \\
\hline Frequency & $1(0-2)$ & $0(0-2)$ & 0.003 \\
\hline Duration & $1(0-2)$ & $0(0-2)$ & 0.003 \\
\hline Table 4. Comparison of Buckley Scores for Group II- Non- \\
Dyspeptic (Median Value) \\
\hline
\end{tabular}

Wilcoxon Rank-Sum test.

\begin{tabular}{|c|c|c|}
\hline Month & $\begin{array}{c}\text { Post-Operative } \\
\text { Score }<=\mathbf{6}\end{array}$ & $\begin{array}{c}\text { Post-Operative } \\
\text { Score }>\mathbf{6}\end{array}$ \\
\hline$<=3$ & $5(16.7 \%)$ & NIL \\
\hline More than 3 & $18(83.3 \%)$ & $7(23.3 \%)$ \\
\hline \multicolumn{2}{|c|}{ Table 5. Duration of Symptom and Post-operative } \\
Buckley Score in Group I (Dyspeptic)
\end{tabular}

Chi-square P value 0.17 .

\begin{tabular}{|c|c|c|}
\hline \multirow{2}{*}{ Episode } & Post-Operative & Post-Operative \\
\cline { 2 - 3 } & Score $<=\mathbf{6}$ & Score $>\mathbf{6}$ \\
\hline <= 3 Episodes & $6(20 \%)$ & NIL \\
\hline > 3 Episodes & $17(56.7 \%)$ & $7(23.3 \%)$ \\
\hline Table 6. Frequency of Episode and Post-operative \\
Buckley Scores in Group I (Dyspeptic) \\
\hline
\end{tabular}

Chi-square p value 0.13 .

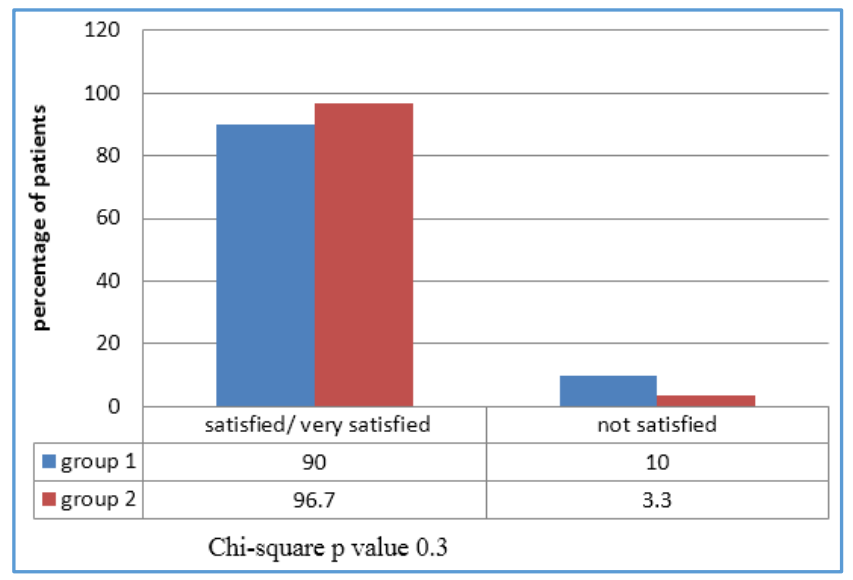

Chart 2. Post-operative Satisfaction in both Group I and Group II-Satisfied or Very Satisfied vs. Not Satisfied

Chi-square $\mathrm{p}$ value 0.3 .

\begin{tabular}{|c|c|c|}
\hline Groups & $\begin{array}{c}\text { Post-operative } \\
\text { Score }<=\mathbf{6}\end{array}$ & $\begin{array}{c}\text { Post-operative } \\
\text { Score }>\mathbf{6}\end{array}$ \\
\hline Group I & $23(76.7 \%)$ & $7(23.3 \%)$ \\
\hline Group II & $25(83.3 \%)$ & $5(16.7 \%)$ \\
\hline $\begin{array}{c}\text { Table 7. Post-operative Satisfaction in both Group I and } \\
\text { Group II in Terms of Post-operative Buckley Score }\end{array}$ \\
\hline
\end{tabular}

\section{DISCUSSION}

\section{Correlation of Findings with Objectives \\ Objective No. 1}

To analyse if laparoscopic cholecystectomy in patients with gall stones and symptom of dyspepsia will give entire relief of symptom. The word entire relief of symptom means entire cessation of symptoms of dyspepsia after the surgery. After laparoscopic cholecystectomy, majority of the patients (76.7\%) in Group I (dyspeptic) achieved complete symptomatic relief 3 months after the surgery as defined by post-operative Buckley scores of less than 6 (Chart 1). Only $23.3 \%$ of Group I (Dyspeptic) patients achieved a Buckley score of more than 6 .

\section{Objective No. 2}

To compare the changes in the pre-operative scores with the post-operative scores and satisfaction after LC in these two groups of patients, i.e. 1) Patients with gall stones and dyspeptic symptoms, 2) Patients with gall stones without dyspeptic symptoms. Group I patients were found to have greater reduction in post-operative Buckley score. Mean cumulative scores of each group as shown in Table 2 reveals a substantial change in score between the pre-operative and post-operative Buckley score, which were very significant. Chart 1 also show the distribution of Buckley score before and after LC for Group I and Group II. These Charts reinforce visually the substantial change between the pre-operative and post-operative Buckley score for both the groups.

\section{Objective No. 3}

To determine the relationship between duration of preoperative episode and the complete resolution of symptom following LC in patients with gall stones and symptom of dyspepsia. Duration is measured by the total time period between onset of symptom and the surgery. All the patients in Group I, those who had the symptoms for less than or equal to 3 months had a Buckley score less than 6 (complete cessation of symptoms) at the end of three months after LC.

\section{Objective No. 4}

To determine the relationship between the frequency of preoperative episode and the complete resolution of symptom after LC in patient with gall stones and symptom of dyspepsia. Frequency is measured by the number of episode in the period of time prior to the surgery. All the patients in Group I, those who had the symptoms of less than or equal to 3 episodes obtained a Buckley score less than 6 at the end of three months after the surgery as evidenced in Table 6 .

\section{CONCLUSION}

The inference of this study shows that-

- Laparoscopic cholecystectomy in patients with gall stones and symptoms of dyspepsia get a better relief of dyspeptic symptoms post-operatively.8,9,10

- Early timely intervention shows a significant change in the pre-operative to the post-operative symptoms and also a significant improvement in satisfaction after the surgery in two groups of patients, i.e. patients with gall stones and dyspeptic symptoms and patients with gall stones and no dyspeptic symptoms.

- $\quad$ Also, the patients who had the symptoms for less than 3 months showed a better improvement in dyspeptic symptoms than the patients who had the symptoms for more than 3 months.

- The patients who had the symptoms for less than or equal to 3 episodes showed a better outcome overall.

\section{Limitation of the Study is Low Sample Size}

Hence, the purpose of this study was to find out the appropriate timing of laparoscopic cholecystectomy in 


\section{Jemds.com}

patients with uncomplicated gallstones disease and dyspeptic symptoms and to establish if the patients get complete symptomatic relief post-operatively.

\section{REFERENCES}

[1] Ros E, Zambon D. Postcholecystectomy symptoms. A prospective study of gall stone patients before and two years after surgery. Gut 1987;28(11):1500-4.

[2] Kim GH, Lee HD, Kim M, et al. Fate of dyspeptic or colonic symptoms after laparoscopic cholecystectomy. J Neurogastroenterol Motil 2014;20(2):253-60.

[3] Lublin M, Crawford DL, Hiatt JR, et al. Symptoms before and after laparoscopic cholecystectomy for gallstones. Am Surg 2004;70(10):863-6.

[4] Shaffer EA, Thomson ABR. First principles of gastroenterology: the basis of disease and approach to management. 5th edn. Toronto: Medicine Group, 2005.

[5] Sherry RM, Gadacz TR. Cholelithiasis and cholecystitis. In: Zuidema GD, Turcotte JG. (eds). Shackelford's surgery of the alimentary tract. Vol III. 4th edn. Philadelphia, WB Saunders C, 1996:229-43.

\section{Original Research Article}

[6] Karam J, Roslyn J. Cholelithiasis and cholecystectomy. In: Zinner MJ, Schwartz SI, Ellis H. (eds). Maingot's abdominal operations. Appleton \& Lange, Stamford, (CT), 1997:1723-5.

[7] Buckley MJ, Scanlon C, McGurgan P, et al. A validated dyspepsia symptom score. Ital J Gastroenterol Hepatol 1997;29(6):495-500.

[8] Mentes BB, Akin M, Irkorucu O, et al. Gastrointestinal quality of life in patients with symptomatic or asymptomatic cholelithiasis before and after laparoscopic cholecystectomy. Surg Endosc 2001;15:1267-72.

[9] Niranjan B, Chumber S, Kriplani AK. Symptomatic outcome after laparoscopic cholecystectomy. Trop Gastroenterol 2000;21(3):144-8.

[10] Vander Velpen GC, Shimi SM, Cuschieri A. Outcome after cholecystectomy for symptomatic gall stone disease and effect of surgical access: laparoscopic $\mathrm{v}$ open approach. Gut 1993;34(10):1448-51. 